\title{
BMJ Open Cohort study evaluating management of burns in the community in clinical practice in the UK: costs and outcomes
}

\author{
Julian F Guest (D) ,1,2 Graham W Fuller, ${ }^{1}$ Jacky Edwards ${ }^{3}$
}

To cite: Guest JF, Fuller GW, Edwards J. Cohort study evaluating management of burns in the community in clinical practice in the UK: costs and outcomes. BMJ Open 2020;10:e035345. doi:10.1136/ bmjopen-2019-035345

- Prepublication history for this paper is available online. To view these files, please visit the journal online (http://dx.doi org/10.1136/bmjopen-2019035345).

Received 28 0ctober 2019 Revised 20 February 2020 Accepted 27 February 2020

Check for updates

(c) Author(s) (or their employer(s)) 2020. Re-use permitted under CC BY-NC. No commercial re-use. See rights and permissions. Published by BMJ.

${ }^{1}$ Catalyst Consultants, Rickmansworth, UK

${ }^{2}$ King's College London, London, UK

${ }^{3}$ Burns Nurse Consultant, Burn Centre, Manchester University NHS Foundation Trust, Manchester, UK

\section{Correspondence to} Dr Julian F Guest; julian.guest@catalyst-health. com

\section{ABSTRACT}

Objective To evaluate health outcomes, resource use and corresponding costs attributable to managing burns in clinical practice, from initial presentation, among a cohort of adults in the UK.

Design Retrospective cohort analysis of the records of a randomly selected cohort of 260 patients from The Health Improvement Network (THIN) database who had 294 evaluable burns.

Setting Primary and secondary care sectors in the UK. Primary and secondary outcome measures Patients' characteristics, wound-related health outcomes,

healthcare resource use and total National Health Service (NHS) cost of patient management.

Results Diagnosis was incomplete in $63 \%$ of patients' records as the location, depth and size of the burns were missing. Overall, $70 \%$ of all the burns healed within 24 months and the time to healing was a mean of 7.8 months per burn. Sixty-six per cent of burns were initially managed in the community and the other $34 \%$ were managed at accident and emergency departments. Patients' wounds were subsequently managed predominantly by practice nurses and hospital outpatient clinics. Forty-five per cent of burns had no documented dressings in the patients' records. The mean NHS cost of wound care in clinical practice over 24 months from initial presentation was an estimated $£ 16924$ per burn, ranging from $£ 12002$ to $£ 40577$ for a healed and unhealed wound, respectively. Conclusions Due to incomplete documentation in the patients' records, it is difficult to say whether the time to healing was excessive or what other confounding factors may have contributed to the delayed healing. This study indicates the need for education of general practice clinicians on the management and care of burn wounds. Furthermore, it is beholden on the burns community to determine how the poor healing rates can be improved. Strategies are required to improve documentation in patients' records, integration of care between different providers, wound healing rates and reducing infection.

\section{INTRODUCTION}

Burns are a serious pathology, potentially leading to severe morbidity and significant mortality. ${ }^{1}$ They can also be among the most expensive traumatic injuries to manage, generating a substantial health economic impact. ${ }^{12}$ In 2012/2013 the UK's National Health Service (NHS) managed an estimated

\section{Strengths and limitations of this study}

This is the first study to evaluate patient pathways and associated health outcomes, resource use and corresponding costs attributable to managing burns across both primary and secondary care over 24 months from initial presentation.

- This study was undertaken using real-world evidence derived from the anonymised records of a sample of patients in The Health Improvement Network (THIN) database (a nationally representative database of clinical practice among $>11$ million patients registered with general practitioners in the UK).

- The estimates were derived following a systematic analysis of patients' characteristics, wound-related health outcomes and all primary and secondary care resource use contained in the patients' electronic records.

- Computerised information in the THIN database is collected by general practitioners for clinical care purposes and not for research; consequently, the accuracy of wound descriptors and other terminology have not been validated, but does reflect real-world documentation in clinical practice.

- The analysis does not consider the potential impact of those wounds that remained unhealed beyond the study period.

87000 burns (excluding chemical and electrical burns) among adults at a cost of $£ 90$ million. ${ }^{34}$ In that year, there were approximately 20000 adult burns-related admissions into hospitals in England, of which $20 \%$ of descriptions lacked specificity. ${ }^{5}$ In 2017/2018, this increased to 23500 adult burns-related admissions into hospitals in England, of which $30 \%$ of descriptions lacked specificity. ${ }^{5}$ Globally, millions of individuals suffer from burn-related injuries each year, ${ }^{6}$ and up to 200000 people die from these injuries, the majority of which occur in low-income and middle-income countries. ${ }^{78}$

In addition to the economic impact, burnrelated injuries can result in functional, psychological and social effects on both survivors and their families. Moreover, non-fatal 
burns are a leading cause of morbidity, disfigurement and disability, often leading to social stigma and rejection. ${ }^{8}$ There are multiple strategies for managing burns and the associated impact on patient physiology, with new care pathways and technology being introduced on a regular basis. ${ }^{9-12}$

A clinician's treatment of choice should be tailored to each patient using updated high-quality scientific evidence. $^{13} 14$ Nevertheless, despite the increasing number of published randomised controlled trials in burn care, systematic reviews have not provided sufficient evidence to support many commonly used interventions or management strategies. ${ }^{15-17}$ Patients who experience a burn represent a heterogeneous population, with variations in age, mechanism of injury, depth, site and size of the burn. Hence, selecting the most important outcomes to measure in burn care is challenging. ${ }^{18}$ Moreover, the follow-up period at which outcomes are measured may also determine the metrics to be assessed, which can include healing time, skin-graft loss, infection rates as well as functional, cosmetic and psychological issues. ${ }^{20}$

Despite this, the authors were unable to find any published evidence on the management of burns and time to healing in clinical practice across the primary and secondary care sectors in the UK. Accordingly, the objective of the present analysis was to follow a cohort of adult patients in clinical practice from initial presentation of their burn to evaluate in greater detail how patients are managed and its impact on healing and NHS costs.

\section{METHODS}

\section{Study design}

This was a retrospective cohort analysis of the case records of adult patients with a burn randomly extracted from The Health Improvement Network (THIN) database. The perspective of the analysis was the NHS's primary and secondary care sectors in the UK and the time horizon was 24 months from initial presentation in the community.

\section{THIN database}

The THIN database contains longitudinal electronic records on $>11$ million anonymised patients entered by general practitioners (GPs) from $>560$ practices across the UK. The patient composition within the THIN database is representative of the UK population in terms of demographics and disease distribution ${ }^{21}$ and the database theoretically contains patients' entire medical history. In particular, the database collects data on the dates that patients registered or left their practice as well as demographic data such as date of birth and gender. Patients who reside at the same address or are members of the same family can be linked using a household identifier, provided they are registered with the same general practice.

All medical conditions and symptoms recorded electronically during a patient's consultation in the general practice are recorded in the THIN database, thereby building up long computerised medical histories using Read Codes. GP prescribing is computerised and entered directly into the database. Prescriptions not issued electronically (eg, during home visits) are also entered, however, there is a possibility of under-recording of such items. Information is also recorded on referrals to secondary care, including the specialty. Secondary care information and other medically related information received by the practice are entered into the database. This includes details on hospital admissions, discharge medication, diagnosis, outpatient consultations, investigations and treatment outcomes. Details from other healthcare interventions, such as information on lifestyle and preventative healthcare, as well as a range of variables such as height, weight, body mass index, blood pressure, smoking and alcohol status, immunisation and laboratory test results are also recorded. Hence, the information contained in the THIN database reflects actual clinical practice.

(THIN is a registered trademark of Cegedim SA in the UK and other countries. Reference made to the THIN database is intended to be descriptive of the data asset licensed by IQVIA).

\section{Study population}

The authors had previously obtained a random sample of records of 6000 adult patients with a documented history of a wound for whatever reason from the THIN database, for previous wound studies. ${ }^{3422-30}$ The study population of 260 patients was identified within this cohort of 6000 patients according to the following criteria:

- Were 18 years of age or over.

- Had a Read Code for a burn including a scald either during or after 2012.

- Had continuous medical history in their case record from the first mention of their wound unless it healed.

- Patients with a Read Code for a chemical or electric burn were excluded from the dataset, and so too were those with a Read Code for sunburn.

- Patients with a Read Code for a dermatological tumour were also excluded from the dataset.

- Any patients with a Read Code for a burn who died within 2 years of initial presentation were also excluded as the study design was to examine the trajectory of these wounds over a full 24 months from initial presentation unless it healed.

\section{Patient and public involvement}

Patients and members of the public were not directly involved in this study. The study population was limited to the anonymised records of patients in the THIN database.

\section{Study variables and statistical analyses}

Information was systematically extracted from the patients' electronic records over 24 months from initial presentation. This included patients' characteristics, comorbidities (defined as a non-acute condition that patients were suffering from in the year before their 
burn), wound-related healthcare resource use (ie, dressings, bandages, topical treatments, district nurse visits (who provide care within a patient's home), practice nurse visits (who provide care within a GP's surgery), GP visits, hospital outpatient visits, hospital admissions, laboratory tests, GP prescribed medication (ie, analgesics, non-steroidal anti-inflammatory drugs and systemic antiinfectives (principally antibiotics)) and clinical outcomes (ie, healing and putative infection). No assumptions were made regarding missing data and there were no interpolations.

Differences between two subgroups were tested for statistical significance using a Mann-Whitney $U$ test or $\chi^{2}$ test. Differences between three subgroups were tested for statistical significance using a Kruskal-Wallis test or $\chi^{2}$ test. Binary logistic regression investigated relationships between baseline variables and clinical outcomes. KaplanMeier analyses were undertaken to compare the healing distribution of different subgroups. The $\mathrm{p}$ values $<0.05$ were considered statistically significant and have been reported. All $p$ values $\geq 0.05$ were not considered to be statistically significant and these numerical values have not been reported. All statistical analyses were performed using IBM SPSS Statistics.

\section{Cost of patient management}

The NHS cost of wound care for each burn was estimated by assigning unit costs at $2017 / 2018$ prices $^{31-33}$ to the number of healthcare resources used to manage individual burns. The mean cost of utilisation of each healthcare resource was then combined in order to estimate the mean NHS cost of managing a burn over 24 months from initial presentation. Accordingly, the study only considers the cost of wound management and does not estimate patients' overall healthcare costs.

\section{Sensitivity analyses}

Deterministic sensitivity analyses were undertaken to assess how the cost of managing a burn changes by varying the values of clinical outcomes and resource use.

\section{RESULTS}

\section{Patients' characteristics}

The study population comprised the anonymised case records of a randomly selected cohort of 260 adult patients from the THIN database who had a burn. According to the records, 26 of these patients had $\geq 2$ burns, resulting in 294 evaluable burns.

The patients' age in the dataset was a mean of $57.8 \pm 18.4$ years per patient, and $61 \%$ were women. Patients had a mean of 4.7 comorbidities and $30 \%$ of patients had diabetes. Characterisation of the burns in the patients' records was poor as $63 \%$ of them lacked documentary evidence of location, depth and size. Patients' baseline characteristics are summarised in table 1.

Seventeen per cent of the wounds were documented as being either scalds or hand burns. An estimated 30\% of
Table 1 Patients' baseline characteristics ( $n=260$ adult patients)

\begin{tabular}{|c|c|}
\hline Mean age at time of presentation (years) & 57.8 \\
\hline Percentage female & $61 \%$ \\
\hline Mean systolic blood pressure $(\mathrm{mm} \mathrm{Hg})$ & 131.4 \\
\hline Mean diastolic blood pressure $(\mathrm{mm} \mathrm{Hg})$ & 75.8 \\
\hline Mean BMI $\left(\mathrm{kg} / \mathrm{m}^{2}\right)$ & 30.2 \\
\hline Percentage with $\mathrm{BMI}<20.0 \mathrm{~kg} / \mathrm{m}^{2}$ & $7 \%$ \\
\hline Percentage with $\mathrm{BMI} \geq 30.0 \mathrm{~kg} / \mathrm{m}^{2}$ & $41 \%$ \\
\hline Percentage who were current smokers & $24 \%$ \\
\hline Percentage who were ex-smokers & $22 \%$ \\
\hline Percentage who were non-smokers & $54 \%$ \\
\hline \multicolumn{2}{|l|}{ Percentage with the following comorbidities } \\
\hline Musculoskeletal & $72 \%$ \\
\hline Cardiovascular & $64 \%$ \\
\hline Endocrinological & $50 \%$ \\
\hline Respiratory & $45 \%$ \\
\hline Dermatological & $43 \%$ \\
\hline Psychiatric & $40 \%$ \\
\hline Gastroenterological & $37 \%$ \\
\hline Neurological & $29 \%$ \\
\hline Genitourinary & $20 \%$ \\
\hline Renal & $20 \%$ \\
\hline Oncological & $19 \%$ \\
\hline Ophthalmological & $16 \%$ \\
\hline Immunological & $10 \%$ \\
\hline Haematological & $5 \%$ \\
\hline \multicolumn{2}{|l|}{ Percentage with the following burns } \\
\hline Unspecified location and depth & $58.8 \%$ \\
\hline Hand (unspecified depth) & $12.9 \%$ \\
\hline Lower limb (unspecified depth) & $9.2 \%$ \\
\hline Upper limb (unspecified depth) & $7.5 \%$ \\
\hline Scald of unspecified location and depth & $4.4 \%$ \\
\hline Trunk (unspecified depth) & $3.4 \%$ \\
\hline Face, head or neck (unspecified depth) & $1.7 \%$ \\
\hline Partial depth (unspecified location) & $1.4 \%$ \\
\hline Full depth (unspecified location) & $0.3 \%$ \\
\hline
\end{tabular}

BMI, body mass index.

these burns occurred in the spring and $<20 \%$ occurred in the summer months. The other wounds occurred with a greater frequency in the winter and spring months.

\section{Clinical outcomes}

In accordance with the study's inclusion criteria, all the patients in our dataset survived the period of 24 months following initial presentation. The THIN database does not define what a wound is, nor does it define wound healing. Wound healing was a clinical observation 


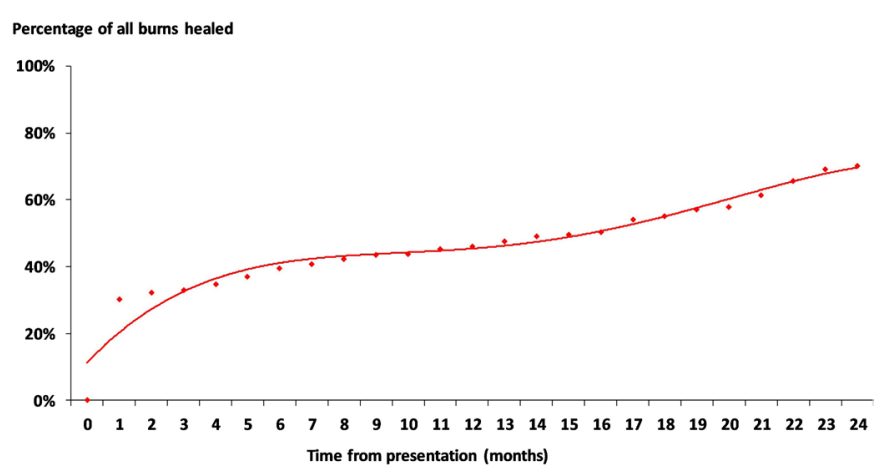

Figure 1 Wound healing.

documented in the patient's record by their managing clinician, but not necessarily confirmed by a specialist, and it is unknown if the clinicians who managed these patients used any consistent definition. Nevertheless, an episode of care was not a proxy for time to healing. On that basis, $30 \%$ of all the burns healed within 1 month, $39 \%$ within 6 months, $46 \%$ within 12 months and a further $24 \%$ by 24 months (a total of $70 \%$ healed within 24 months; figure 1), and the time to healing among the healed wounds was a mean of 7.8 months per burn. More specifically, $9 \%$ of all the burns were managed exclusively in primary care and they all healed within 2 months. A total of $77 \%$ of all the burns managed by burns services healed and their time to healing was a mean of 8.8 months per burn, whereas $50 \%$ of the burns managed by plastic surgery services healed and their time to healing was a mean of 15 months per burn. Of the wounds managed by a non-specified service, $66 \%$ healed and their mean time to healing was 8.6 months. There were minimal differences in the comorbidity profile between patients whose wound healed and those that remained unhealed. However, $>25 \%$ of patients with a documented scald or hand burn had an opthalmological comorbidity compared with $16 \%$ of patients with other wounds $(\mathrm{p}<0.03)$.

\section{Patient management}

According to the records, $66 \%$ of burns were initially managed in the community at a patient's general practice before being referred to a hospital outpatient clinic. The other $34 \%$ were initially managed at accident and emergency departments. Of the patients who were managed at accident and emergency departments, $15 \%$ were subsequently admitted into hospital (of which $1 \%$ underwent surgery) and $19 \%$ were managed as outpatients. Over the 24 months from the burn injury, patients were predominantly managed by practice nurses and seen in a hospital outpatient clinic between one and four times a month until the wound healed. Ongoing resource use after initial presentation is summarised in table 2.

Fifty-five per cent of the burns were treated with dressings and the other $45 \%$ had no documented evidence in the patients' records of dressings having been used. Table 3 summarises the dressings that were prescribed. Up to $41 \%$ of burns were treated with multiple dressings (mean of 2.7 dressings per burn). Documentation in the patients' records suggests that patients would receive a dressing in a hospital outpatient clinic, but after subsequent attendance at their general practice, they would either receive a combination of dressings or no dressings at all. Furthermore, the percentage of patients who received multiple dressings increased the longer the patient had their wound (figure 2).

\section{Cost of patient management}

The mean NHS cost of wound care in clinical practice over 24 months was an estimated $£ 16924$ per burn. However, the cost of managing an unhealed burn was significantly more than that of managing a healed burn ( $£ 12002$ vs $£ 40,577 ; \mathrm{p}<0.001$ ) (table 4 ). Hospital admissions were the primary cost driver and accounted for $52 \%$ of the cost of wound management. Hospital outpatient visits and general practice visits were the secondary cost

Table 2 Healthcare resource use associated with managing burns in clinical practice ( $\mathrm{n}=294$ burns)

\begin{tabular}{llc} 
& \multicolumn{2}{l}{ Resource use over 24 months from initial presentation } \\
\cline { 2 - 3 } Resource & Percentage of burns & Mean number per burn \\
\hline Practice nurse visits & 98 & 54.8 \\
GP visits & 97 & 23.5 \\
Outpatient clinic visits & 91 & 22.2 \\
District nurse visits & 18 & 1.9 \\
Accident and emergency attendances & 34 & 1.9 \\
Medical admissions (no surgery) & 28 & 0.9 \\
Surgical admissions & 4 & 0.05 \\
Dressings & 55 & 457.8 \\
\multicolumn{1}{c}{ Single dressings } & 14 & 128.3 \\
\hline Multiple dressings & 41 & 672.0 \\
\hline Prescriptions for analgesics and non-steroidal anti-inflammatories & 68 & 8.7 \\
\hline
\end{tabular}

GP, general practitioner. 


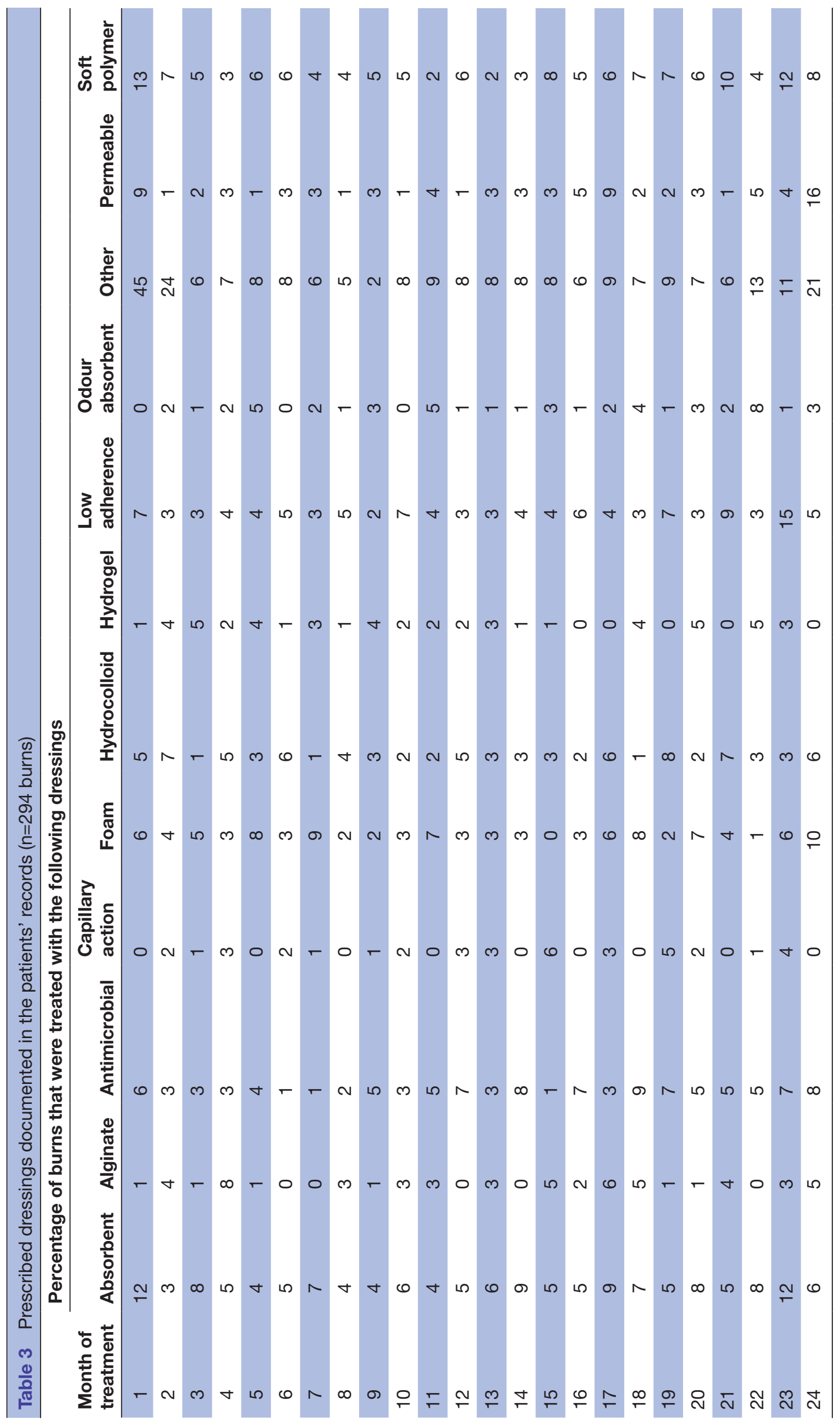

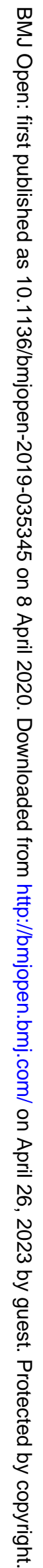




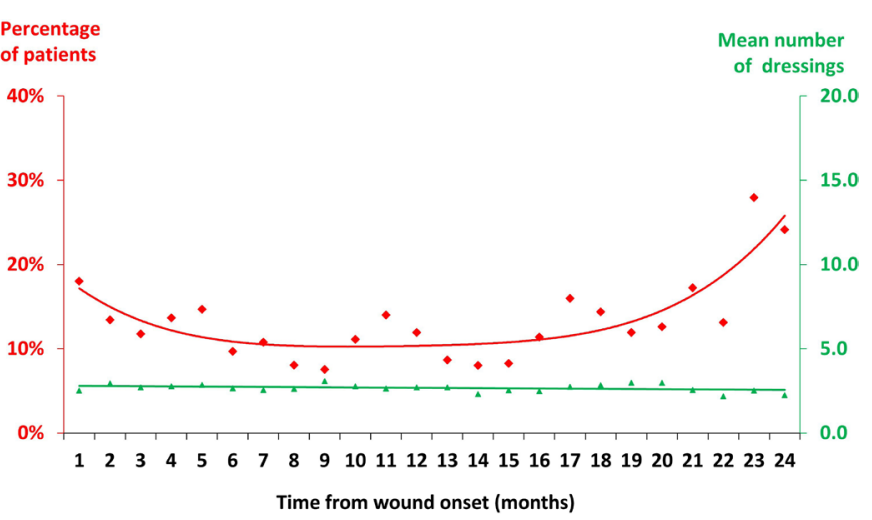

Figure 2 Patients who received multiple dressings.

drivers accounting for $15 \%$ and $12 \%$ of the cost of wound management, respectively. Dressings and bandages accounted for up to $6 \%$ of the cost of wound management. Of the total NHS cost of managing a burn, 27\% was incurred in the community and the remainder in secondary care. Furthermore, the distribution of costs was unaffected by whether the wound healed. Figure 3 illustrates how the monthly cost of wound management decreased for both healed and unhealed burns.

\section{Antimicrobial dressings and antibiotics}

Sixty percent of the burns were recorded as being treated with either an antimicrobial dressing or systemic antibiotic or a combination of both. The other $40 \%$ of burns had no documented evidence of having received either in the patients' records. (table 5). The healing rate was similar among both groups. However, the time to healing

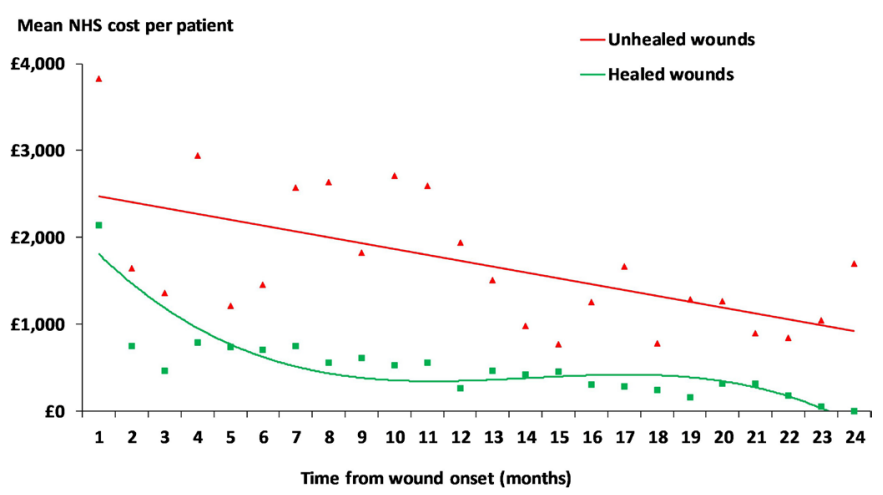

Figure 3 Monthly NHS cost of wound care at 2017/2018 prices. NHS, National Health Service.

was substantially longer among those burns that were recorded as having been treated with an antimicrobial dressing and/or an antibiotic and the cost of wound management increased accordingly (table 5).

Kaplan-Meier analyses demonstrated that the time to healing distribution was significantly different between wounds in the two groups $(p<0.001)$ even though there was no significant difference in the overall probability of being healed by 24 months (figure 4 ).

\section{Body mass index (BMI)}

The healing rate increased in parallel with increasing BMI, and so too did the cost of wound management (table 6). Kaplan-Meier analyses (figure 5) demonstrated that the time to healing distribution was not significantly different between patients with a different BMI $(\mathrm{p}=0.191)$,

Table 4 Cost of healthcare resource use associated with managing burns $(n=294)$ in clinical practice at 2017/2018 prices (percentage of the total cost is within parenthesis)

\begin{tabular}{|c|c|c|c|c|c|c|}
\hline \multirow{3}{*}{$\begin{array}{l}\text { Resource } \\
\text { Medical admissions (no surgery) }\end{array}$} & \multicolumn{6}{|c|}{ Mean cost of resource use per burn over 24 months from initial presentation } \\
\hline & \multicolumn{2}{|l|}{ All burns } & \multicolumn{2}{|c|}{ Healed burns } & \multicolumn{2}{|c|}{ Unhealed burns } \\
\hline & $£ 8879.70$ & (52) & $£ 6292.18$ & (52) & $£ 21347.72$ & (53) \\
\hline Outpatient visits & $£ 2601.60$ & (15) & $£ 1931.91$ & (16) & $£ 5897.84$ & (15) \\
\hline GP visits & $£ 2004.80$ & (12) & $£ 1501.41$ & (13) & $£ 4488.47$ & (11) \\
\hline Practice nurse visits & $£ 1314.30$ & (8) & $£ 975.89$ & (8) & $£ 2976.36$ & (7) \\
\hline Dressings & $£ 850.00$ & (5) & $£ 462.60$ & (4) & $£ 2573.34$ & (6) \\
\hline Surgical admissions & $£ 524.70$ & (3) & $£ 323.42$ & (3) & $£ 1449.60$ & (4) \\
\hline $\begin{array}{l}\text { Accident and emergency } \\
\text { attendances }\end{array}$ & $£ 318.00$ & (2) & $£ 228.31$ & (2) & $£ 752.81$ & (2) \\
\hline Community nurse visits & $£ 117.40$ & (1) & $£ 59.69$ & $(<1)$ & $£ 356.33$ & (1) \\
\hline Bandages & $£ 120.40$ & (1) & $£ 76.82$ & (1) & $£ 322.52$ & (1) \\
\hline $\begin{array}{l}\text { Prescriptions for analgesics and } \\
\text { non-steroidal anti-inflammatories }\end{array}$ & $£ 150.90$ & (1) & $£ 119.37$ & (1) & $£ 313.96$ & (1) \\
\hline Other wound care products & $£ 34.70$ & $(<1)$ & $£ 25.11$ & $(<1)$ & $£ 81.35$ & $(<1)$ \\
\hline Ambulance transportation & $£ 5.70$ & $(<1)$ & $£ 4.80$ & $(<1)$ & $£ 10.75$ & $(<1)$ \\
\hline Laboratory tests & $£ 1.70$ & $(<1)$ & $£ 0.82$ & $(<1)$ & $£ 5.61$ & $(<1)$ \\
\hline Total & $£ 16923.90$ & (100) & $£ 12002.33$ & (100) & $£ 40576.66$ & (100) \\
\hline
\end{tabular}

GP, general practitioner. 
Table 5 Cost of wound care stratified by infection management

\begin{tabular}{|c|c|c|c|c|}
\hline & $\begin{array}{l}\text { Percentage } \\
\text { of cohort }\end{array}$ & $\begin{array}{l}\text { Percentage } \\
\text { healed }\end{array}$ & $\begin{array}{l}\text { Time to } \\
\text { healing } \\
\text { (months) }\end{array}$ & $\begin{array}{l}\text { Mean } \\
\text { cost of } \\
\text { care }\end{array}$ \\
\hline No evidence of having received antibiotics and/or antimicrobial dressings & $40 \%$ & $69 \%$ & 3.4 & $£ 4379$ \\
\hline Recorded as having received antibiotics and/or antimicrobial dressings & $60 \%$ & $66 \%$ & 11.2 & $£ 26671$ \\
\hline Recorded as having received only antibiotics & $43 \%$ & $71 \%$ & 10.7 & $£ 24396$ \\
\hline Recorded as having received only antimicrobial dressings & $4 \%$ & $50 \%$ & 5.1 & $£ 12606$ \\
\hline
\end{tabular}

and even though the probability of healing among those with a BMI $\geq 20 \mathrm{~kg} / \mathrm{m}^{2}$ was approximately a third more than those with a $\mathrm{BMI}<20 \mathrm{~kg} / \mathrm{m}^{2}$, the Odds ratio did not reach statistical significance. The lack of statistical significance between those with a BMI $\geq 20 \mathrm{~kg} / \mathrm{m}^{2}$ and those with a BMI $<20 \mathrm{~kg} / \mathrm{m}^{2}$ may be due to the small sample size. A retrospective power calculation estimated that 125 patients in each group would be required to demonstrate this observation with $80 \%$ power and a type 1 error of 0.05 .

\section{Sensitivity analyses}

Sensitivity analyses showed that if the probability of healing was reduced by $25 \%$, from $70 \%$ to $53 \%$, the mean NHS cost of wound care over 24 months would increase by $24 \%$ to an estimated $£ 20920$ per wound. Conversely, if the probability of healing was increased by $25 \%$, from $70 \%$ to $88 \%$, the mean NHS cost of wound care over 24 months would decrease by $19 \%$ to an estimated $£ 12693$ per wound.

If the number of hospital admissions changed by $25 \%$ below or above the base case value, the mean NHS cost of wound care over 24 months would vary by $14 \%$ from the mean value (range: £14591-19257 per burn). However, if the number of hospital outpatient visits changed by $25 \%$ below or above the base case value, the mean NHS cost of wound care over 24 months would vary by $4 \%$ from the mean value (range: $£ 16266-17582$ per burn) and if the number of general practice visits changed by $25 \%$ below or above the base case value, the mean NHS cost of wound care would vary by $3 \%$ from the mean value (range: $£ 16412-17436$ per burn). If the unit cost of wound care products was decreased or increased by $25 \%$, the mean NHS cost of wound care over 24 months would only vary by $1 \%$ from the mean value (range: $£ 16684-17164$ per

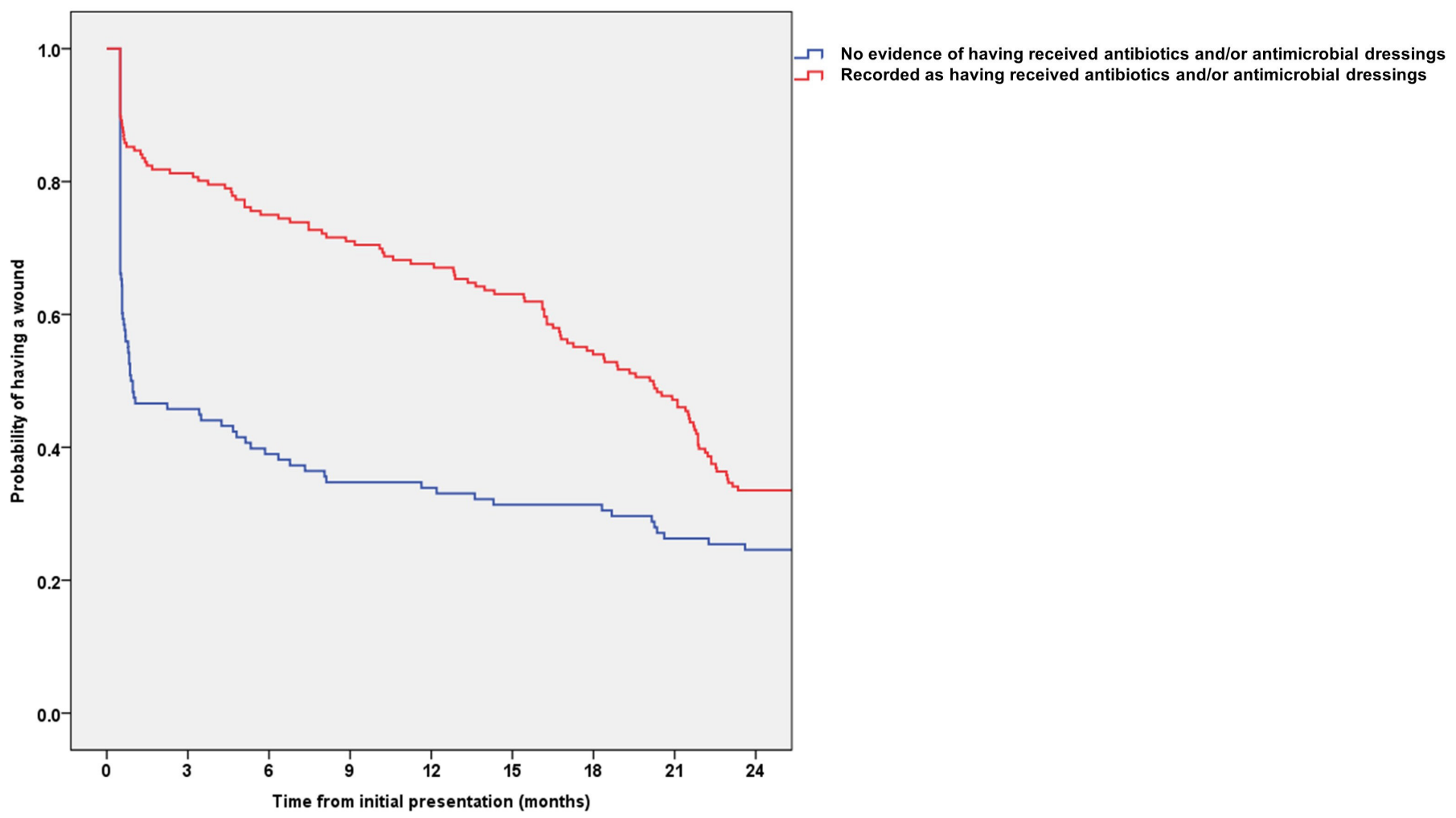

Figure 4 Kaplan-Meier analysis of infection. 


\begin{tabular}{|c|c|c|c|}
\hline BMI $\left(\mathrm{kg} / \mathrm{m}^{2}\right)$ & $\begin{array}{l}\% \text { of } \\
\text { Patients }\end{array}$ & $\%$ Healed & $\begin{array}{l}\text { NHS cost per } \\
\text { patient }\end{array}$ \\
\hline$<20$ & 7 & 55 & $£ 9411$ \\
\hline 20-29 & 41 & 66 & $£ 11485$ \\
\hline 30-35 & 27 & 74 & $£ 15143$ \\
\hline$>35$ & 20 & 83 & $£ 20049$ \\
\hline
\end{tabular}

BMI, body mass index; NHS, National Health Service.

burn). Changes to other model inputs had a minimal impact on the mean NHS cost of wound care in clinical practice.

\section{DISCUSSION}

This study aimed to investigate fire-related burns and scalds, hence, those with a chemical or electric burn were excluded from the analysis. The study population of 260 adult patients with 294 evaluable burns may not necessarily be representative of the total adult population with a burn in the UK, given their significant number of comorbidities. Nevertheless, this study provides a snapshot of how patients are managed across different services that have been difficult to ascertain from other published studies. Furthermore, the study raises questions about 'burn wound chronicity'. There is a paucity of evidence on burn wound chronicity and it is not well recognised in the literature; in fact, a Medline/Cinahl search for chronic burn wounds between 1980 and 2019 identified only eight articles. All were written by surgeons, taking a surgical perspective to wound management or Marjolin's ulcers of $\geq 10$ years duration. The majority of the articles were from developing countries where delays in presentation and healing are common. Only one study assessed a chronic burn wound and the effect that biofilm may have on wound healing, but this was a single case study. ${ }^{34}$ Even within these articles, the suggested treatments for chronic burn wounds were predominantly debridement,
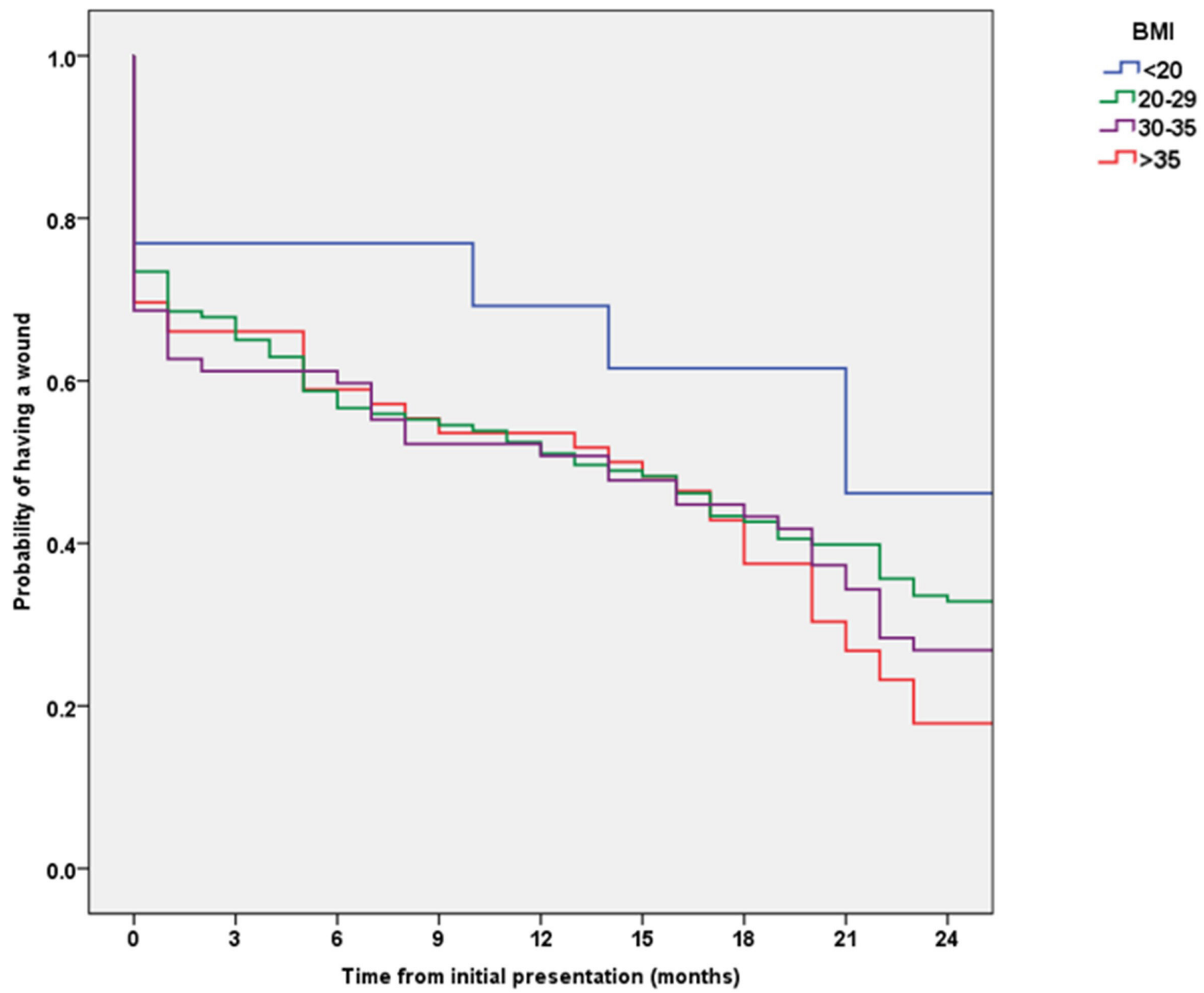

Figure 5 Kaplan-Meier analysis of BMI $\left(\mathrm{kg} / \mathrm{m}^{2}\right)$. BMI, body mass index. 
infection control and promotion of granulation tissue. ${ }^{35}$ This lack of identification of chronicity means that modern treatments, such as biofilm-based wound care, protease modulators, electrostimulation and so on are not used routinely on non-healing burn wounds. ${ }^{36}$ In the absence of published time to healing estimates for burn wounds in the UK, it is not possible to compare the healing outcomes in this retrospective study and to elucidate whether the estimated time to healing is extreme.

Notwithstanding this, the delayed time to healing could be due to either inadequate assessment and referral to specialist services, or lack of education around burn wound management and/or recognition and appropriate treatment of a chronic burn wound (ie, some of the wounds could have become chronic in nature, but were continued to be treated as an acute burn wound). There is also the possibility that some nurses continued to treat the burn scar as a wound, which is sometimes seen in clinical practice. As the depth was rarely documented in the records of this study's patients, it is difficult to ascertain whether these burn wounds should all have healed by 3 weeks or should have had some surgical intervention within the first 3 weeks. Nevertheless, there is definitely a need for burn specialists to understand the pathophysiology of chronic wounds and apply the current up-to-date wound treatments to the chronic burn wound.

A burn injury can be one of the most severe forms of trauma and to achieve the best possible clinical outcome, burn care must be delivered by expert multidisciplinary teams in specialised burns services. ${ }^{37}$ In the UK, there is significant variation in the way burns are managed and followed-up by burns services. Some services will regularly review the patient in their own clinics until the wound is healed, whereas other services will either teach patients to undertake self-care or use a shared-care model with either the community nursing team or practice nurses. Hence, very few patients with a burn wound are managed exclusively by practice nurses. The authors were unable to verify from documentation in the patients' records which model of care was used for each patient and whether they were followed-up by specialist services to full healing. Nevertheless, nearly all the patients in this study's cohort were jointly managed in both hospital outpatient clinics and by their general practice. It was interesting to note that wounds referred to specialist services seemed to take longer to heal, possibly due to them being deeper and larger injuries which were appropriately referred to specialist services. However, the burns managed by plastic surgery services took almost twice as long to heal and this could be due to the 'hub and spoke' arrangements in some parts of the UK (ie, plastic surgeons who do not usually manage burns were seeing these wounds in satellite clinics with no support from burns or plastic surgery trained nurses or in services that predominantly only treat plastic surgery patients rather than burns). Of concern, in particular, is the time to healing of the wounds that were seen in burn clinics; although they managed to heal more patients $(77 \%)$, the mean time to healing of 8.8 months probably relates back to the issues of not acknowledging burn wound chronicity and therefore amending treatments appropriately. Additionally, over the study's follow-up period of 24 months, 32\% of all the burns resulted in hospital admission.

Nonetheless, there was minimal evidence of a co-ordinated shared treatment plan between primary and secondary care. Documentation in the patients' records suggests that in the majority of instances, the dressings patients received in a hospital outpatient clinic were changed by clinicians in general practice and they would often be switched from a single to multiple dressings or no dressings at all. The goals of local burn wound management are the prevention of desiccation of viable tissue and control of bacteria through moist wound healing. ${ }^{38}$ Hence, dressings removed by practice nurses are often reinstated in specialist clinics. One of the challenges to improving burn care in the community is the variable extent to which employers release and fund training and development of practice nurses. ${ }^{39}$ Consequently, this study's wounds may have taken longer to heal if wound care was not the primary area of expertise of the nurses caring for these patients in the community. A series of Link Nurse Frameworks for burns has been developed across the Burns Care Operational Delivery Networks. However, despite their in-reach into both emergency departments and community nurses, very little impact has been made on practice nurses as access to these healthcare professionals has proved difficult. ${ }^{40}$ Clearly, improving integration in management practices between secondary and primary care should lead to a better outcome for patients and would be cost-effective for the NHS.

The severity of a burn relates to both the depth of skin involvement and the percentage of the total body surface area involved. ${ }^{41}$ Hence, the lack of documentation pertaining to diagnosis was particularly worrying. An estimated $63 \%$ of the records lacked a specific burn or scald location, depth and size, $35 \%$ only specified location but not depth and size, and another $2 \%$ specified depth but not location and size. Consequently, any reporting system based on patients' records in primary care or the community would lead to an under-reporting and be inaccurate.

The patients in this study seemed to have had significantly more comorbidities than the burn patients in the International Burn Injury Database, ${ }^{42}$ and that may have contributed to the length of time taken for their wounds to have healed. It is unusual for GPs to become involved with the management of a burn wound, and this may be due to this cohort being more at risk due to their comorbidities. Nevertheless, there is still an issue surrounding the lack of burn care education among primary care clinicians. Moreover, $60 \%$ of all the burns in this cohort were considered to be infected or at risk of infection, based on documentation in the patients' records. Wound infections are one of the most serious problems that occur in the acute phase after a burn injury. ${ }^{43}$ Several factors contribute to infection in burn wounds, notably the destruction of the skin barrier, the presence 
of necrosis and serosanguinous exudate, and impaired immune function. ${ }^{44}$ Only superficial burn wounds will heal with minimal risk of infection; all other depths have the potential for colonisation and, thus, infection. ${ }^{43}$ The risks are commensurate with the depth and extent of the burn, the health and age of the patient and local perfusion of the tissues. Local burn wound management is one of the most important aspects of burn therapy after the emergency treatment phase and can have considerable influence on time to healing. ${ }^{45}$ For this reason, deeper wounds should always be managed with antimicrobials to prevent infection. Church et al argue that the widespread application of an effective topical antimicrobial agent substantially reduces the microbial load on the open burn wound surface and reduces the risk of infection. ${ }^{46}$ In the majority of burn units in the UK, antibiotics are not routinely administered prophylactically to burn patients because of concerns regarding antibiotic resistance, high cost and the risk of adverse drug effects. ${ }^{44}$ However, they are routinely given to patients with burn injuries by either emergency departments or GPs as there is a lack of understanding of the normal inflammatory process of a burn. In this cohort, only $17 \%$ of all the burns were treated with an antimicrobial dressing at some point during the study's follow-up period. Consequently, the antimicrobial use may have been appropriate, but without adequate assessment of depth, a judgement cannot be made. Furthermore, there was no documentary evidence of $45 \%$ of patients ever having received a dressing for their wound, although there is no consensus on which agent or dressing is optimal for burn wound coverage to prevent or control infection or to enhance wound healing. ${ }^{47} 48$

Resource use associated with managing a wound treated with antibiotics and/or antimicrobial dressings was found to be greater than that of a wound treated with neither, as the time to healing was longer. So too was resource use associated with managing the wounds that remained unhealed compared with those that went on to heal. Consequently, the cost of managing an unhealed wound was at least three times more than that of managing a healed wound (mean of $£ 40600$ vs $£ 12000$ per wound), and the cost of managing a wound not treated with antibiotics and/or antimicrobial dressings was at least $80 \%$ less than that of a wound treated with either. These findings are consistent with our Burden of Wounds study. ${ }^{3428}$ The time to healing a wound is an important factor in driving costs. Accordingly, the cost of burn wound management can be affected by a combination of resources required for dressing changes, the complexity of some treatment regimens and infection. It is also noteworthy that the healing rate was higher among patients with a higher BMI, which was contrary to the healing rate among a cohort of patients with unhealed surgical wounds. ${ }^{26}$

This study provided insights into areas where improvements in clinical and service management could potentially enhance healing and other patient outcomes while reducing overall management costs. These are:
- Working to common definitions and reporting standards across primary and secondary care.

- Integrating care across providers.

- Rational use of products with access to advanced wound treatments when necessary.

- Recognising comorbidity management as appropriate.

In turn, with improved healing, these actions should reduce workload and associated healthcare resource use and lead to reductions in the overall cost of wound care. All healthcare systems recognise the importance of managing patients with a burn and the relative risk of developing an infection. Clearly, training non-specialist nurses in the appropriate management of burn wound care is a prerequisite to overcoming some of the problems encountered in clinical practice and to achieving better health outcomes than those currently being observed.

Forty-six per cent of all the burns in this study had healed by 12 months from the time of the injury. In comparison, we previously estimated that $53 \%$ of venous leg ulcers (VLUs), ${ }^{30} 35 \%$ of diabetic foot ulcers (DFUs), ${ }^{27} 50 \%$ of community-acquired pressure ulcers (PU) (ranging from $100 \%$ for category 1 ulcers to $21 \%$ for category 4 ulcers) $)^{25}$ and $83 \%$ of surgical wounds ${ }^{26}$ healed within 12 months from the onset of community management. The 12-monthly cost of a wound that healed was £3,000, $£ 2,100, £ 5100$ and $£ 6000$ for a VLU, DFU, communityacquired PU and surgical wound, respectively, ${ }^{25-27} 30$ compared with $£ 8800$ for a healed burn. Additionally, the 12-monthly cost of a wound that remained unhealed by 12 months was $£ 13,500, £ 8,800, £ 12300$ and $£ 13700$ for a VLU, DFU, community-acquired PU and surgical wound, respectively, ${ }^{25-2730}$ compared with $£ 26700$ for an unhealed burn. The higher burn-associated costs reflect the higher proportion of these injuries that result in a hospital admission and the majority of the burns being managed in both hospital outpatient clinics and by community-based teams. The authors were unable to find any recent studies reporting the cost of managing adult burns in the UK. In one earlier study, the mean treatment cost over the 2011/2012 financial year associated with patients allocated to different burn-specific healthcare resource groups ranged from £2528 to £31871 (uprated to $£ 3088$ and $£ 36,074$, respectively, at $2017 / 2018$ prices). ${ }^{49}$ Comparison with our study may not be appropriate because of changes in patient management, hospital admission pathways and healthcare resource use over the intervening period. A systematic review of articles on burn-related costs published from 1950 to 2012 estimated the mean total healthcare cost per burn patient in highincome countries to be US $\$ 88,218$ ( $£ 66205$ ) (range: US $\$ 704-U S \$ 717,306$ ( $\$ 536-£ 546447)$ ). ${ }^{50}$ However, comparisons are ineligible because of differences in methodological approaches, patient pathways and unit costs.

\section{Study limitations}

The advantages and disadvantages of using patients' records in the THIN database for health economic studies in wound care have been previously discussed. ${ }^{3}$ 
In summary, the advantage of using the database is that the patient pathways and associated resource use are based on real-world evidence derived from clinical practice. However, the analyses were based on clinicians' entries into their patients' records and inevitably subject to a certain amount of imprecision and lack of detail. Moreover, the computerised information in the database is collected by GPs and nursing teams for clinical care purposes and not for health economics research. Prescriptions issued by GPs and practice nurses are recorded in the database, but it does not specify whether the prescriptions were dispensed or detail patient compliance with the product. There may also be an underrecording of community-based clinician visits outside of the general practice. Despite these limitations, it is the authors' opinion that the real-world evidence contained in the THIN database has provided a useful perspective on the management of burns in clinical practice in the UK and the associated costs.

The analysis was truncated at 24 months and does not consider the potential impact of those burns that remained unhealed beyond the study period. The analysis only considered NHS resource use and associated costs for the 'average patient' and was not stratified according to gender, comorbidities, disease-related factors and level of clinicians' skills. Costs incurred by non-NHS organisations (such as the provision of social care), patients' costs and indirect societal costs as a result of patients being absent from work were also excluded from the analysis.

\section{CONCLUSIONS}

Due to incomplete documentation in the patients' records, it is difficult to say whether the time to healing was excessive or what other confounding factors may have contributed to the delayed healing. Nevertheless, this study indicates the need to educate general practice clinicians on the management and care of burn wounds. Furthermore, it is beholden on the burns community to determine how the poor healing rates can be improved. Clinical and economic benefits to both patients and the NHS could accrue from strategies that focus on improving documentation in patients' records, the integration of care between different providers, wound healing rates and reducing infection.

Contributors JFG: designed the study, managed the analyses, performed some analyses, checked all the other analyses and wrote the manuscript; guarantor of this work and, as such, had full access to all the data in the study and takes responsibility for the integrity of the data and the accuracy of the data analysis. GWF: conducted much of the analyses. JE: scrutinised the analyses, suggested further analyses and helped interpret some of the findings. All the authors were involved in revising the manuscript and gave final approval.

Funding This study was funded by JFG, the lead author, without any external support.

Competing interests None declared.

Patient and public involvement Patients and/or the public were not involved in the design, or conduct, or reporting, or dissemination plans of this research.

Patient consent for publication Not required.
Ethics approval Ethics approval to use anonymised patients' records from the THIN database for this study was obtained from the Research Ethics Committee that appraises studies using the THIN database (reference number 13-061).

Provenance and peer review Not commissioned; externally peer reviewed.

Data availability statement All data relevant to the study are included in the article or uploaded as supplementary information. The THIN dataset cannot be shared as this restriction was a condition of the ethics approval obtained from the Research Ethics Committee (reference number 13-061). Questions concerning the data underlying the results can be sent to the Corresponding Author.

Open access This is an open access article distributed in accordance with the Creative Commons Attribution Non Commercial (CC BY-NC 4.0) license, which permits others to distribute, remix, adapt, build upon this work non-commercially, and license their derivative works on different terms, provided the original work is properly cited, appropriate credit is given, any changes made indicated, and the use is non-commercial. See: http://creativecommons.org/licenses/by-nc/4.0/.

ORCID iD

Julian F Guest http://orcid.org/0000-0003-0162-2007

\section{REFERENCES}

1 Brusselaers N, Monstrey S, Vogelaers D, et al. Severe burn injury in Europe: a systematic review of the incidence, etiology, morbidity, and mortality. Crit Care 2010;14:R188.

2 Nair CKV, Gopinath V, Ashok VG. Demographic and socio-cultural aspects of burns patients admitted in a tertiary care centre. International Surgery Journal 2017;4:2170.

3 Guest JF, Ayoub N, Mcllwraith T, et al. Health economic burden that wounds impose on the National health service in the UK. BMJ Open 2015;5:e009283.

4 Guest JF, Ayoub N, Mcllwraith T, et al. Health economic burden that different wound types impose on the UK's National health service. Int Wound J 2017;14:322-30.

5 NHS England. Hospital episode statistics: England. Available: https:// digital.nhs.uk/data-and-information/publications/statistical/hospitaladmitted-patient-care-activity

6 Peck M, Molnar J, Swart D. A global plan for burn prevention and care. Bull World Health Organ 2009;87:802-3.

7 Mock C, Peck M, Peden M, et al. A who plan for burn prevention and care. Geneva: World Health Organization, 2008.

8 World Health Organization. Burns fact sheet, 2018. Available: https:// www.who.int/news-room/fact-sheets/detail/burns

9 Atiyeh BS, Hayek SN, Gunn SW. New technologies for burn wound closure and healing-review of the literature. Burns 2005;31:944-56.

10 Wounds Internationa. In: Wounds Internationals. International best practice guidelines: wound management in diabetic foot ulcers, 2013. Available: www.woundsinternational.com

11 Rowan MP, Cancio LC, Elster EA, et al. Burn wound healing and treatment: review and advancements. Crit Care 2015;19:243.

12 Avita Medical RECELL $®$ System Health Economic Data Project USD \$28 Million in Annual Savings at a Single Major Burn Center Versus Standard of Care, 2019. Available: https://www.biospace.com/article/ releases/avita-medical-recell-system-health-economic-data-projectusd-28-million-in-annual-savings-at-a-single-major-burn-centerversus-standard-of-care/

13 Metzdorff MT. Evidence-based medicine: what it is, what it isn't, and are we practicing it? J Trauma Acute Care Surg 2013;75:927-35.

14 Djulbegovic B, Elqayam S. Many faces of rationality: implications of the great rationality debate for clinical decision-making. J Eval Clin Pract 2017;23:915-22.

15 Flores O, Stockton K, Roberts JA, et al. The efficacy and safety of adrenergic blockade after burn injury: a systematic review and metaanalysis. J Trauma Acute Care Surg 2016;80:146-55.

16 Avni T, Levcovich A, Ad-El DD, et al. Prophylactic antibiotics for burns patients: systematic review and meta-analysis. BMJ 2010;340:c241.

17 Aziz Z, Abu SF, Chong NJ. A systematic review of silver-containing dressings and topical silver agents (used with dressings) for burn wounds. Burns 2012;38:307-18.

18 Klein MB, Goverman J, Hayden DL, et al. Benchmarking outcomes in the critically injured burn patient. Ann Surg 2014;259:833-41.

19 Pereira C, Murphy K, Herndon D. Outcome measures in burn care. is mortality dead? Burns 2004;30:761-71.

20 Holavanahalli RK, Helm PA, Kowalske KJ. Long-Term outcomes in patients surviving large burns: the musculoskeletal system. $J$ Burn Care Res 2016;37:243-54. 
21 Blak BT, Thompson M, Dattani H, et al. Generalisability of the health improvement network (thin) database: demographics, chronic disease prevalence and mortality rates. Inform Prim Care 2011;19:251-5.

22 Panca M, Cutting K, Guest JF. Clinical and cost-effectiveness of absorbent dressings in the treatment of highly exuding VLUs. $J$ Wound Care 2013;22:109-18.

23 Guest JF, Gerrish A, Ayoub N, et al. Clinical outcomes and costeffectiveness of three alternative compression systems used in the management of venous leg ulcers. J Wound Care 2015;24:300-10.

24 Guest JF, Fuller GW, Vowden P. Clinical outcomes and costeffectiveness of three different compression systems in newly-diagnosed venous leg ulcers in the UK. J Wound Care 2017;26:244-54.

25 Guest JF, Fuller GW, Vowden P, et al. Cohort study evaluating pressure ulcer management in clinical practice in the UK following initial presentation in the community: costs and outcomes. BMJ Open 2018;8:e021769.

26 Guest JF, Fuller GW, Vowden P. Costs and outcomes in evaluating management of unhealed surgical wounds in the community in clinical practice in the UK: a cohort study. BMJ Open 2018;8:e022591.

27 Guest JF, Fuller GW, Vowden P. Diabetic foot ulcer management in clinical practice in the UK: costs and outcomes. Int Wound $J$ 2018;15:43-52.

28 Guest JF, Vowden K, Vowden P. The health economic burden that acute and chronic wounds impose on an average clinica commissioning group/health board in the UK. J Wound Care 2017;26:292-303.

29 Guest JF, Taylor RR, Vowden K, et al. Relative cost-effectiveness of a skin protectant in managing venous leg ulcers in the UK. $J$ Wound Care 2012;21:389-98.

30 Guest JF, Fuller GW, Vowden P. Venous leg ulcer management in clinical practice in the UK: costs and outcomes. Int Wound $J$ 2018;15:29-37.

31 Curtis L, Burns A. Unit costs of health and social care 2018. University of Kent, personal social services research unit, Canterbury, 2018. Available: https://kar.kent.ac.uk/70995/ [Accessed 25 Jul 2019].

32 Department of Health. National schedule of NHS reference costs 2017/18. Available: https://improvement.nhs.uk/resources/referencecosts/ [Accessed 25 Jul 2019].

33 Drug Tariff. Drug tariff, 2018. Available: https://www.drugtariff.co.uk [Accessed 25 July 2019].
34 Ramos-Gallardo G. Chronic wounds in burn injury: a case report on importance of biofilms. World J Plast Surg 2016;5:175-80.

35 Maher A. Establishing a consensus for the surgical management of chronic burn wounds: a randomised prospective comparative study. Egypt J Plast Reconstr Surg 2009;33:31-7.

36 Edwards J. Burn wound chronicity - myth or reality? Wounds UK 2013;9:4-5

37 Al-Mousawi AM, Mecott-Rivera GA, Jeschke MG, et al. Burn teams and burn centers: the importance of a comprehensive team approach to burn care. Clin Plast Surg 2009;36:547-54.

38 Wounds International. International best practice guidelines: effective skin and wound management of non-complex burns, 2016 Available: https://www.woundsinternational.com/resources/details/ best-practice-guidelines-effective-skin-and-wound-management-innon-complex-burns

39 The Queen's Nursing Institute. General practice nursing in the 21st century: a time of opportunity, 2016. Available: https://www.qni.org uk/wp-content/uploads/2016/09/gpn_c21_report.pdf

40 Edwards J. Developing a burns link nurse framework for minor burn management. Wounds UK 2013;9:10-13.

41 Benson A, Dickson WA, Boyce DE. Burns. BMJ 2006;332:649-52.

42 Stylianou N, Buchan I, Dunn KW. A review of the International burn injury database (iBID) for England and Wales: descriptive analysis of burn injuries 2003-2011. BMJ Open 2015;5:e006184.

43 Edwards J. Use of Silvercel non-adherent on burn wounds: a case series. Wounds UK 2013;9:81-4.

44 Edwards-Jones V, Greenwood JE. What's new in burn microbiology? Burns 2003;29:15-24.

45 Atiyeh BS, Ibrahim A, Hayek S N. Burn wound cleansing: an efficient evidence-based treatment modality or a ritualistic practice. $J$ Wound Technol 2010;7:6-10.

46 Church D, Elsayed S, Reid O, et al. Burn wound infections. Clin Microbiol Rev 2006;19:403-34.

47 Wasiak J, Cleland H, Campbell F, et al. Dressings for superficial and partial thickness burns. Cochrane Database Syst Rev 2013;3:CD002106.

48 Norman G, Christie J, Liu Z, et al. Antiseptics for burns. Cochrane Database Syst Rev 2017;7:CD011821.

49 Jeevan R, Rashid A, Lymperopoulos NS, et al. Mortality and treatment cost estimates for 1075 consecutive patients treated by a regional adult burn service over a five year period: the Liverpool experience. Burns 2014:40:214-22.

50 Hop MJ, Polinder S, van der Vlies $\mathrm{CH}$, et al. Costs of burn care: a systematic review. Wound Repair Regen 2014;22:436-50. 